\title{
Booms and Busts as Exchange Options
}

\author{
Stephen Matteo Miller* \\ Monash University, Australia
}

Selling (buying) a country's equity index in exchange for equity investments elsewhere during a stock market crash (boom) is analogous to exercising an option to exchange an underperforming country (global benchmark) index for a global benchmark (country) index. This can be shown by extending an existing single factor option pricing framework to determine the exchange option value of entering and exiting an emerging market. As country betas, corrected for non-synchronous trading bias, rise during the Asian Crisis and fall thereafter, exit option values on average increase by at least 14 cents per dollar invested for each unit increase in country betas during the first stage of the crisis in 1997. Exit option values on average rise by 29 cents per dollar invested during the last stage in January 1999. So even if the benefits of diversification fall during a crisis, the effects of a crisis might be hedged. (JEL: F30; F36; G2; G15)

Keywords: Country Systematic Risk and Risk-Adjusted Performance; Exchange Options; International Transmission; Net Capital Flow Monitoring; Non-synchronous Trading Bias

\section{Introduction}

Equity market booms and busts can be replicated as exchange options; thinking about them this way may open the way to replicating and hedging against such events. Here, Okunev and Tippet's (1993) single factor option pricing framework is used to compute the overnight value of investing in a country during a boom. The entry exchange option contract that characterizes a boom pays when a country's global systematic risk adjusted performance exceeds that for a broad global stock market index, and equals zero otherwise. Okunev and Tippett do

\footnotetext{
* Department of Economics, Monash University, Victoria 3800, Australia. Tel.: +(03) 9905-2320; fax: +(03) 9905-5476. E-mail address: stephen.miller@monash.edu.

(Multinational Finance Journal, 2012, vol. 16, no. 3/4, pp. 189-223)

(C) Multinational Finance Society, a nonprofit corporation. All rights reserved. DOI: $10.17578 / 16-3 / 4-2$
} 
not consider the put option, but by using their Put-Call Parity condition, the exit exchange option that characterizes a bust is derived. It pays the difference between global systematic risk-adjusted performance on a broad global stock market index and a country's stock index if this difference is positive, and equals zero otherwise.

The options considered here relate to Merton's (1990), Bodie and Merton's (2002) and Draghi et al.'s (2003) suggestion that global capital flow volatility might be hedged with traded financial instruments. The example they give involves global and local investors entering into swap contracts written on the return differential between a small emerging market and some proxy for the world portfolio. At year's end, small market (foreign) investors receive compensation if the return on the $i^{\text {th }}$ small country index exceeds (falls short of) the return on the world index.

In a related effort, Miller (2005) estimates a rolling variant of Jensen's (1968) "alpha" for thirteen emerging markets, suggesting that it could be used as the underlying index in a swap contract. The country alpha measures the difference between the average return on a country's index and the product of the country's contribution to global systematic risk, or "beta", with the average return on the world index. The alphas and betas are adjusted for non-synchronous trading bias using a simplified version of Scholes and Williams's (1977) method, since markets operate at different hours during the day, such that closing index values do not arrive at the same time. Country alpha swaps with a strike set to zero might then work, so that hedging demanders (suppliers) are compensated when a country's alpha is negative (positive) if they take short (long) positions in country alpha swaps. The patterns exhibited by the combined entry-exit exchange option payouts here resemble the country alphas, since the key input in both the exchange option and the country alpha swap is a daily, rolling, country beta. This suggests that a short (long) position on a country alpha swap is analogous to the exit exchange option (entry exchange option).

The problem here also relates to the literature on investment decisions as options. For instance, the exit problem considered here can be related to the literature on divestitures as abandonment options (e.g., Clark et al. (2010)). The divestiture is modeled directly here since investors generally handle the underlying exit in the open market where prices are observed, unlike a corporate divestiture, where investors handle the divestiture behind closed doors as they may dispute the value of a previously untraded accounting entity. Alternatively, another way 
would be to think about the timing problem (e.g., Amin and Bodurtha (1995) and Fruhwirth et al. (2007)). In this paper, the time to invest/disinvest arises when the country's equity index outperforms/underperforms the global equity benchmark.

Since the exchange options discussed here are not yet traded it is not possible to analyze the problem here using implied risk measures. To understand why, Siegel (1995) shows that if an option is created to exchange a security for a broad market portfolio, or vice versa, and then if it trades in the marketplace, the implied risk measure is no longer simply the volatility as in Latane and Rendleman (1976). It also includes an implied systematic risk measure, or beta, which is not observable. Instead, the beta risk input is estimated using a rolling variant of the method proposed by Scholes and Williams (1977), to correct for possible non-synchronous trading bias that arises as markets operate in different time zones, and then used as an input to get the theoretical option prices.

During normal times on average the entry exchange option values drop by 15 cents per dollar invested in a country for a one unit increase in the country's beta; ceteris paribus, more systematic risk reduces the value of investing in a country. In contrast, the exit exchange option value is unrelated to country systematic risk in normal times. However, during the Asian Crisis, that all changes, as the sensitivity of exit exchange option values to country systematic risk rises by 14 cent per dollar invested in the first stage, rises further to 19 cents per dollar invested in the second stage, falls back to zero during the Russian default, but rises again to 29 cents per dollar invested in the last stage of the Asian Crisis when the Brazilian real floats. This finding is important, because it suggests that even if the benefits of diversification may fall during a crisis, as Roll (1988), Chakrabarti and Roll (2002) and Acker and Duck (2009) among others suggest, the risks might still be hedged. Not surprisingly, the sensitivity of entry exchange option values to changes in country systematic risk falls during the Crisis.

Even if the ideas here never make it to market, the formula to price such options may be useful for monitoring net capital flows, which as reported by Bordo et al. (2004), is a task viewed as increasingly important by officials at the International Monetary Fund (IMF). Just as the credit default swap market provides information to the marketplace about likelihood of default, the methodology here provides a high-frequency measure of the willingness to pay to get into or out of a country. The entry and exit exchange option pricing formulas are 
presented before using the methodology to compute the inputs is described, and after describing the data, and revisiting the key events of the Asian Crisis, the value of exiting and entering an emerging market is analyzed, before concluding.

\section{Valuing Capital Flight with Exchange Options}

\section{A. The Single Factor Option Pricing Model in A Global Equity Market World $^{1}$}

To understand the entry and exit options first consider Okunev and Tippett's (1993) single factor call and put option pricing framework, a special case of their multi-factor option pricing framework. Their framework extends the Black-Scholes methodology to value market risks beyond firm-specific risk. Since they assume a domestic asset pricing context, in the single factor case, the relationship they define is between the stock price for a particular company and the domestic stock market index. Therefore, the beta in their model is akin to the beta in Black and Scholes's (1973) "alternative derivation," or in Merton's (1973) intertemporal capital asset pricing model, when the investment opportunity set is constant.

Okunev and Tippett's (1993) framework can also be applied in the context of a reduced form of Solnik's (1974a) international asset pricing model, by assuming either fixed, or perfectly hedged exchange rates, so that the returns are denominated in a single currency. As Chakrabarti and Roll (2002) argue, assuming a single currency is like taking a global portfolio manager's home currency perspective, rather than looking at it from the perspective of a central banker, who may be interested in what role the exchange rate played in a crash. Since the aim here is to suggest a way for global investors to hedge against the rise in country systematic risk during a crisis, US dollar-denominated returns are used throughout.

To derive the single factor call and put options, assume first that the global index denominated in US dollars follows Geometric Brownian Motion (GBM), while a country index, also denominated in US dollars, follows a continuous-time, single factor model. Using subscript $w$ to

1. I am grateful to Mark Tippett for a helpful discussion concerning the option pricing framework. 
indicate the world index and subscript $k$ to indicate the country index, the instantaneous changes in the value of the indices are denoted, respectively, as

$$
\begin{gathered}
\frac{d V_{W}}{V_{W}}=\mu_{w} d t+\sigma_{w} d z_{w} \\
\frac{d V_{k}}{V_{k}}=\alpha_{k w} d t+\beta_{k w} \frac{d V_{w}}{V_{w}}+\sigma_{k} d z_{k}
\end{gathered}
$$

where $V_{k}$ and $V_{w}$ are the country and global equity index values, respectively, $\mathrm{dt}$ is an increment of time, $\mu_{w}$ is the expected return on the global index, $d z_{k}$ and $d z_{w}$ are unit normal Wiener processes, $\sigma_{k}$ and $\sigma_{w}$ are the volatility scaling parameters, the former capturing country-specific idiosyncratic risk and the latter representing global systematic risk, $\beta_{k w}$ measures a country's contribution to global systematic risk, and $\alpha_{k w}$ can be thought of as a measure of risk-adjusted profit. Substituting equation 1 into 2 yields

$$
\frac{d V_{k}}{V_{k}}=\alpha_{k w} d t+\beta_{k w}\left(\mu_{w} d t+\sigma_{w} d z_{w}\right)+\sigma_{k} d z_{k}
$$

The solutions to the stochastic differential equations in equations 1 and 3 are, respectively

$$
V_{w T}=V_{w t} \exp \left\lfloor\left(\mu_{w}-1 / 2 \sigma_{w}^{2}\right)(T-t)+\sigma_{w}\left(z_{w T}-z_{w t}\right)\right\rfloor
$$

and

$$
\begin{gathered}
V_{k T}=V_{k t}\left(\frac{V_{w T}}{V_{w t}}\right)^{\beta_{k w}} \\
\exp \left[\left(\alpha_{k w}+\frac{1}{2}\left(\beta_{k w}\left(1-\beta_{k w}\right) \sigma_{w}^{2}-\sigma_{k}^{2}\right)\right)(T-t)+\sigma_{k}\left(z_{k T}-z_{k t}\right)\right]
\end{gathered}
$$

Taking expectations of equations 1 and 3, respectively, yields 


$$
E\left[\frac{d V_{w}}{V_{w}}\right]=\mu_{w} d t
$$

and

$$
E\left[\frac{d V_{k}}{V_{k}}\right]=\mu_{k} d t=\alpha_{k w} d t+\beta_{k w} \mu_{w} d t
$$

By the rules of stochastic calculus, the relevant expression for the variance of the world benchmark is

$$
E\left[\left(\frac{d V_{w}}{V_{w}}\right)^{2}\right]=\sigma_{w}^{2} d t
$$

and the country's total risk is

$$
E\left[\left(\frac{d V_{k}}{V_{k}}\right)^{2}\right]=\left(\beta_{k w}^{2} \sigma_{w}^{2}+\sigma_{k}^{2}\right) d t
$$

By rearranging equation 7 and dividing through by dt, this leads to a simplified expression for alpha as the systematic risk-adjusted, excess expected return, or

$$
\alpha_{k w}=\mu_{k}-\beta_{k w} \mu_{w}
$$

If this is not zero, then it will signify that there are arbitrage opportunities.

In this simple bi-variate framework, the boundary conditions for the single-factor call option-pricing formula for a particular country index would be

$$
C\left(V_{k}, S, 0\right)=\begin{aligned}
& V_{k}-S, \text { if } V_{k}>S \\
& 0, \quad \text { if } V_{k} \leq S
\end{aligned}
$$

where $C$ is the call option price, $V_{k}$ is the value of the country index, $S$ is the strike price. This states that the option pays out if the country's index value exceeds the strike, otherwise it equals zero. By applying Ito's lemma to the call option price, Okunev and Tippett (1993) show 
that it is homogenous of degree one in terms of the stock and the market portfolio. As a result, the partial differential equation they derive has only second order terms, as the first order terms, excluding the time derivative, cancel, yielding

$$
1 / 2 \frac{\partial^{2} C}{\partial V_{k}^{2}} V_{k}^{2}\left(\beta_{k w}^{2} \sigma_{w}^{2}+\sigma_{k}^{2}\right)+1 / 2 \frac{\partial^{2} C}{\partial V_{w}^{2}} V_{w}^{2} \sigma_{w}^{2}+\frac{\partial^{2} C}{\partial V_{k} \partial V_{w}} V_{k} V_{w} \beta_{k w} \sigma_{w}^{2}+\frac{\partial C}{\partial t}=0
$$

The solution differs slightly from the formula proposed by Black and Scholes (1973) in both the volatility input, and the absence of a risk-free rate of return and reduces to

$$
C\left(V_{k}, S, T-t\right)=V_{k} N\left(d_{1}\right)-S N\left(d_{2}\right)
$$

where $d_{1}$ and $d_{2}$ are defined, respectively, as

$$
d_{1}=\frac{\ln \left(\frac{V_{k}}{S}\right)+\frac{1}{2}\left[\sigma_{w}^{2}\left(1-\beta_{k w}\right)^{2}+\sigma_{k}^{2}\right](T-t)}{\sqrt{\left(\sigma_{w}^{2}\left(1-\beta_{k w}\right)^{2}+\sigma_{k}^{2}\right)(T-t)}}
$$

and

$$
d_{2}=\frac{\ln \left(\frac{V_{k}}{S}\right)-1 / 2\left[\sigma_{w}^{2}\left(1-\beta_{k w}\right)^{2}+\sigma_{k}^{2}\right](T-t)}{\sqrt{\left(\sigma_{w}^{2}\left(1-\beta_{k w}\right)^{2}+\sigma_{k}^{2}\right)(T-t)}}
$$

Okunev and Tippett (1993) give two reasons why the market portfolio does not seem to appear. First, the market portfolio is redundant, if investors have access to the option and the underlying company shares. In addition, they show that even after including a risk-free asset, the stock and option are still shown to be sufficient to span all possible states of nature. A second reason why the market portfolio does not appear is that its presence is implied via the underlying stock's expected return, as the $\sigma_{w}^{2}$ and $\beta_{k w}$ terms are included in the volatility term. Assuming no transaction costs, Put-Call Parity in the framework simplifies to

$$
C+S=V_{k}+P
$$


where $P$ is the put option price, and all other variables are defined as before. From this, Okunev and Tippett (1993) derive the put option pricing formula

$$
P\left(V_{k}, S, T-t\right)=S N\left(-d_{2}\right)-V_{k} N\left(-d_{1}\right)
$$

with $d_{1}$ and $d_{2}$ defined as above.

The country idiosyncratic risk parameter $\sigma_{k}^{2}$ together with the global risk factors $\sigma_{w}^{2}, \beta_{k w}$ appear priced factors in equations 13 and 15 , as well as in the entry and exit options discussed next. This makes it possible to allow for Girard and Sinha's (2006) observation that both local and global risk can be priced factors in emerging markets.

\section{B. The Entry Exchange Option}

Using this option pricing formula, Okunev and Tippett (1993) then reconsider Margrabe's (1978) example of the performance management fee, noting that his formula for the fee omits systematic risk. Okunev and Tippett (1993) derive the fee from a portfolio's excess gross, systematic risk-adjusted return

$$
\text { Entry }=\$ W \cdot\left(\frac{V_{k T}}{V_{k t}}-\left(\frac{V_{w T}}{V_{w t}}\right)^{\beta_{k w}}\right)
$$

The logic here is that for every dollar invested, the manager for fund $k$ should only be compensated for beating the market, after adjusting for the amount of systematic risk inherent in fund $k$. Okunev and Tippett's formula relaxes the assumption implicit in Margrabe's formula that each country is as risky as the global market $w\left(\beta_{k w}=1\right)$, but for all countries studied here $\beta_{k w}$ almost never equals 1 .

Okunev and Tippett show that, given the following terminal values

$$
C\left(V_{k}, V_{w}, 0\right)=\begin{aligned}
& V_{k T}-V_{k t}\left(\frac{V_{w T}}{V_{w t}}\right)^{\beta_{k w}}, \text { if } V_{k T} \geq V_{k t}\left(\frac{V_{w T}}{V_{w t}}\right)^{\beta_{k w}} \\
& 0, \quad \text { if } V_{k T}<V_{k t}\left(\frac{V_{w T}}{V_{w t}}\right)^{\beta_{k w}}
\end{aligned}
$$


the entry exchange option is the price of a call option, where the underlying is the price of terminal relative to initial values of the country index, while the random strike is the price of terminal relative to initial values on the global benchmark, multiplied beta times, or

$$
C\left(V_{k}, V_{w}, T-t\right)=\frac{V_{k T}}{V_{k t}} N\left(d_{1}\right)-\left(\frac{V_{w T}}{V_{w t}}\right)^{\beta_{k w}} N\left(d_{2}\right)
$$

with $d_{1}$ and $d_{2}$ now defined as

$$
d_{1}=\frac{\ln \left(\frac{V_{k T}}{V_{k t}}\left(\frac{V_{w T}}{V_{w t}}\right)^{-\beta_{k w}}\right)+1 / 2\left[\sigma_{w}^{2}\left(1-\beta_{k w}\right)^{2}+\sigma_{k}^{2}\right](T-t)}{\sqrt{\left(\sigma_{w}^{2}\left(1-\beta_{k w}\right)^{2}+\sigma_{k}^{2}\right)(T-t)}}
$$

and

$$
d_{2}=\frac{\ln \left(\frac{V_{k T}}{V_{k t}}\left(\frac{V_{w T}}{V_{w t}}\right)^{-\beta_{k w}}\right)-1 / 2\left[\sigma_{w}^{2}\left(1-\beta_{k w}\right)^{2}+\sigma_{k}^{2}\right](T-t)}{\sqrt{\left(\sigma_{w}^{2}\left(1-\beta_{k w}\right)^{2}+\sigma_{k}^{2}\right)(T-t)}}
$$

As discussed at the outset, this has a useful interpretation in this study because it gives the value of investing in a country that is outperforming the global benchmark index. With that in mind, the value of exiting a country that is underperforming a global benchmark index, which rises during financial crises, is derived next.

\section{The Exit Exchange Option}

In the case of exit, a global investor seeks protection from underperformance, rather than compensation for outperformance, and wants a contract specified as ${ }^{2}$

2. The exit option is a variant of Jaeger and Zimmerman's (1995) notion of "benchmark insurance" that they introduce as an application of Margrabe's (1978) pricing formula to value surplus insurance. 


$$
\text { Exit }=\$ W \cdot\left(\left(\frac{V_{w T}}{V_{w t}}\right)^{\beta_{k w}}-\frac{V_{k T}}{V_{k t}}\right)
$$

After setting $\beta_{k w}=1$, by replacing total returns with rates of return this resembles the underlying in the swap contract discussed by Merton (1990). Given equation 19 and the following terminal values

$$
P\left(V_{k}, V_{w}, 0\right)=\begin{array}{ll}
0, & \text { if } V_{k T} \geq V_{k t}\left(\frac{V_{w T}}{V_{w t}}\right)^{\beta_{k w}} \\
\left(\frac{V_{w T}}{V_{w t}}\right)^{\beta_{k w}} V_{k t}-V_{k T}, & \text { if } V_{k T}<V_{k t}\left(\frac{V_{w T}}{V_{w t}}\right)^{\beta_{k w}}
\end{array}
$$

the exit exchange option can be defined as the put option price.

To obtain a put pricing formula, apply Put-Call Parity, assuming zero transaction costs, and rewrite equation 14 as the price of a call plus the difference between the relative price of the global index to the beta power and the relative price of the country index, or

$$
P=C+\left(\frac{V_{w T}}{V_{w t}}\right)^{\beta_{k w}}-\frac{V_{k T}}{V_{k t}}
$$

Substituting equation 18 into this Put-Call parity condition yields

$$
\begin{aligned}
P\left(V_{k}, V_{w}, T-t\right) & =\frac{V_{k T}}{V_{k t}} N\left(d_{1}\right)-\left(\frac{V_{w T}}{V_{w t}}\right)^{\beta_{k w}} N\left(d_{2}\right)+\left(\frac{V_{w T}}{V_{w t}}\right)^{\beta_{k w}}-\frac{V_{k T}}{V_{k t}} \\
& =\frac{V_{k T}}{V_{k t}}\left[N\left(d_{1}\right)-1\right]-\left(\frac{V_{w T}}{V_{w t}}\right)^{\beta_{k w}}\left[N\left(d_{2}\right)-1\right] \\
& =\left(\frac{V_{w T}}{V_{w t}}\right)^{\beta_{k w}} N\left(-d_{2}\right)-\frac{V_{k T}}{V_{k t}} N\left(-d_{1}\right)
\end{aligned}
$$

where $d_{1}$ and $d_{2}$ are computed as for the entry exchange option. As 
defined, if a country's index under-performs the global benchmark, the option pays that difference; otherwise, it has no value. This is the price of disinvesting from that country. The discussion next turns to estimating inputs to estimate the entry and exit option values.

\section{Estimated Inputs for the Single-Factor Option Pricing Formula}

The Black-Scholes formula requires only a single volatility estimate, but the single-factor option pricing model has three required risk inputs: the country's idiosyncratic risk, the country's contribution to global systematic risk or beta risk, and global systematic risk. Since the aim here is to see how the value of both entering and exiting a country varies over time, the option formula inputs must also be tracked. In what follows, rolling regression coefficients and volatilities along with the daily country and global index closing values are used to track the price of entering and leaving a country over time. ${ }^{3}$ In general, the rolling estimator requires choosing a sub-set of the first $w$ data points in a time series of $T$ observations, and applying the estimator to each of $T-w-$ 1 sub-samples by rolling the "window" forward in time. Here, $w$ is fixed at 250 observations, roughly one year of trading days, so that the estimates reflect roughly one year of the most recent trading activity.

An additional problem that occurs when working with daily close-to-close return data from markets in different time zones. For instance, markets in East Asia open and close before those in Europe, the Middle East and Africa, which in turn close before those in North and South America. Therefore, a moving windows variant of Harvey's

3. The rolling estimator is used because, barring any data revisions, the time-path of historical estimates is always fixed for a particular sample of data. This property is desirable if, the framework here might be used to track market sentiments over time, after updating the sample. The fixity of the estimates does not hold for conditional beta estimators. For instance, in an early draft of this paper, a multi-variate Generalized Autoregressive Conditional Heteroscedasticity (M-GARCH) framework was used to estimate the country betas and show how simply changing one or both sample endpoints changes the entire sample path of M-GARCH country beta estimates. For instance, the July 2, 1997 M-GARCH country beta for Indonesia, estimated using data from July $3^{\text {rd }}, 1995-J u l y ~ 2^{\text {nd }}, 1997$, could be very different from the July 2, 1997 M-GARCH country beta estimated using updated data from July $3^{\text {rd }}$, 1995-January 9, 2006. If used as an option pricing model input the time path of option prices would also change as the sample endpoints changed. The same short-coming would apply to more general M-GARCH specifications such as Butler and Okada's (2008). 
(1995) framework that applies the Scholes and Williams (1977) OLS regression adjustment procedure to correct for non-synchronous data is applied to the empirical analog of equation 2 proposed by Solnik (1974b). ${ }^{4}$ One implication of non-synchronous trading bias is that assets that trade more or less frequently than the market will have downward biased betas, while assets trading as frequently as the market will have upward biased betas.

Also, in studies that make use of monthly return data a risk-free asset is typically essential. Scholes and Williams (1977) work with daily data, and the risk-free rate of return during such intervals is typically close to zero, so risk free assets are not used here. Another reason not to include the risk free rate is that, it is a redundant security in Okunev and Tippett's (1993) framework.

The daily Scholes and Williams's (1977) betas can be constructed as follows

$$
\beta_{k w t}^{S}=\frac{\beta_{k w t}^{+}+\beta_{k w t}+\beta_{k w t}^{-}}{1+2 \cdot \rho_{w t}}
$$

where $\beta_{k w t}^{+}$is the one-day leading beta, $\beta_{k w t}$ is the contemporaneous beta, $\beta_{k w t}^{-}$is the one-day lagging beta, and $\rho_{w t}$ is the world market autocorrelation coefficient. As this method is well known, a more detailed expression of these regressions is left in the appendix. The time subscript $t$ reflects the fact that the parameters are estimated using sub-samples of 250 observations, so that it can vary over time.

Like the betas, the Scholes-Williams alphas must also be constructed as

$$
\alpha_{k w t}^{S}=\bar{r}_{k, t-1, t-248}-\beta_{k w t}^{S} r_{w, t-1, t-248}
$$

where $r_{k, t-1, t-248}$ and $r_{w, t-1, t-248}$ are respectively, the average dollar-denominated returns for country $k$ and the world index $w$, estimated between day $t-1$ and $t-247$, and the superscript $S$ refers to the estimate being corrected for non-synchronous trading bias. The presence of non-synchronous trading bias implies that alphas for assets trading

4. An alternative approach might involve directly accounting for the effect of time differences on the risk measures as Kahya (1997) suggests. However, the Emerging Markets Database used here does not report the trading hours for the shares used in the country indices. 
more or less frequently than the market will be upward biased, while assets trading as frequently as the market will be downward biased. ${ }^{5}$

The country idiosyncratic risk, $\sigma_{k}^{2}$, can be estimated by calculating the variance, $\sigma_{e_{k t}^{s}}^{2}$, of the residuals constructed from the rolling alphas, betas and a window of past returns

$$
\left(\begin{array}{c}
e_{k, t}^{S} \\
e_{k, t-1}^{S} \\
\vdots \\
e_{k, t-249}^{S}
\end{array}\right)=\left(\begin{array}{c}
r_{k, t} \\
r_{k, t-1} \\
\vdots \\
r_{k, t-249}
\end{array}\right)-\alpha_{k w t}^{S}\left(\begin{array}{c}
1 \\
1 \\
\vdots \\
1
\end{array}\right)+\beta_{k w t}^{S}\left(\begin{array}{c}
r_{w, t} \\
r_{w, t-1} \\
\vdots \\
r_{w, t-249}
\end{array}\right)
$$

Finally, the estimates of the global variance are adjusted using Scholes and Williams's (1977) suggestion. They define the relationship between the estimated autocorrelation coefficient and variance of benchmark portfolio returns and the true variance in their equation 18 as

$$
\rho_{w}=1 / 2\left[\frac{\sigma_{\text {True }, w}^{2}}{\sigma_{w}^{2}}-1\right]
$$

The autocorrelation will be positive if the observed variance is less than the true variance. A rolling version of the true variance in equation 26 is estimated to solve for the true variance

$$
\sigma_{\text {True }, w t}^{2}=\left(1+2 \cdot \rho_{w t}\right) \sigma_{w t}^{2}
$$

The $\rho_{w t}$ and all other auto-correlation coefficients, are estimated using a rolling regression because there are times when the rolling Maximum Likelihood AR(1) estimator reports null values, but the estimated time-paths otherwise track one another closely. The events of the Asian Crisis are summarized before discussing the data used to estimate the rolling alphas, betas and standard errors, and the entry and exit option prices.

5. McDonald et al. (2009) show that another source of bias may arise from assuming away skewness in the error distribution, when in fact it exist 


\section{The Asian Crisis and Investable Emerging Equity Market Data}

\section{A. The Asian Crisis Revisited}

The series of events of concern here is the Asian Crisis, which has been summarized in a number of places. ${ }^{6}$ The country in which the crisis begins to unfold is Thailand, already in 1996, where an insolvent financial services firm is forced to close by the Thai Central Bank. For the next year the Thai baht is subjected to speculative attacks until July 2, 1997, when the Thai Central Bank introduces a managed float, replacing the existing pegged exchange rate regime, which marks the beginning of the first phase of the Asian Crisis. The result is a devaluation of between 15-20\%. By July 11, the Philippine Central Bank is forced to abandon its peg, while the Indonesian Central Bank widens the range of the exchange rate band. This is followed three days later by the collapse of the Malaysian ringitt peg. One month later, the Indonesian rupiah band can no longer be defended resulting in the currency's depreciation. On October 17, 1997, the Taiwanese new dollar is allowed to float, and for the next week, global investors anticipate the end of the Hong Kong Monetary Authority's quasi-currency board-like arrangement. On October 27, 1997, the Dow Jones falls over 500 points, similar in magnitude, but much smaller in percentage terms, than the October 1987 crash. A few weeks later on November 17, 1997 the South Korean central bank floats the won. January $15^{\text {th }}$ and $16^{\text {th }}$ mark the signing of the International Monetary Fund (IMF) agreement with Indonesia, and the rolling over of debts to South Korea, and the end of the first phase of the Asian Crisis. ${ }^{7}$

A second period of turmoil unfolds during the second quarter of 1998, from about April 1st, through June $30^{\text {th }}, 1998$. Then on August $17^{\text {th }}, 1998$, the Russian government defaults on its debt, marking the beginning of the third stage of the Asian Crisis. On September 1, 1998, President Mahatir in Malaysia imposes capital controls, which results in the country's securities being delisted from the ACWI on September

6. See for instance, International Monetary Fund (1998, 1999, 2003), and Kaminski and Schmukler (1999).

7. See International Monetary Fund (1998), ibid 
TABLE 1. Newsworthy Events During Recent Financial Crises

\begin{tabular}{|c|c|}
\hline Dates & Event \\
\hline July 2, 1997 & $\begin{array}{l}\text { Thai baht floats, Philippine peso and Malaysian ringitt peg } \\
\text { collapse shortly thereafter, and the Indonesia rupiah band is } \\
\text { widened }\end{array}$ \\
\hline August 28, 1997 & Short-selling restrictions imposed in Malaysia \\
\hline October 17,1997 & The Taiwanese new dollar floats \\
\hline November 17,1997 & The South Korean won floats \\
\hline January 15,1998 & $\begin{array}{l}\text { The IMF standby agreement with Indonesia isimplemented; } \\
\text { major banks roll-over Korean government debts the next day }\end{array}$ \\
\hline May 21, 1998 & Indonesian President Suharto resigns after riots and civil unrest \\
\hline August 17, 1998 & The Russian Ministry of Finance effectively defaults on its debt \\
\hline September 1, 1998 & Capital controls implemented in Malaysia \\
\hline January 13, 1999 & $\begin{array}{l}\text { Brazilian central banker resigns in response to pressure to } \\
\text { abandon the real peg }\end{array}$ \\
\hline February 1, 1999 & Asian Crisis ends \\
\hline
\end{tabular}

$30^{\text {th }}, 1999 .{ }^{8}$ The last phase of the Asian Crisis occurs in mid-January 1999 when the Brazilian central bank widens the real band.

\section{B. Daily Data}

In deciding how to best measure performance, some, such as Ranaldo and Haberle (2008) have suggested that equally-weighted indices may better reflect passive investment strategies, and therefore serve as better benchmarks than market capitalization-weighted indices. However, Tabner (2009) argues that market capitalization-weighted indices are closer in spirit to the notion of an efficient market portfolio as implied by the capital asset pricing model. They also show that market capitalization-weighted indices have lower tail risk than equally-weighted indices during a down-turn, precisely the type of event studied here. Market capitalization-weighted indices are accordingly used.

8. See http://www.mscibarra.com/eqb/methodology/meth_docs/MSCI_May06_Index CalcMethodology.pdf. The securities were later relisted on May $31^{\text {st }}, 2000$. It is tempting to think that the delisting from the ACWI benchmark index might affect the estimated coefficients for Malaysia, however, the patterns in resemble those for other countries in the region. 
The source of data for the emerging markets used here is the Standard \& Poor's (S\&P) Emerging Markets Database (EMDB) described by Edison and Warnock (2003). It includes daily index closing values for "investable" and "global" equities, the former (latter) representing those available to all investors (a country's residents). S\&P analysts determine if a reasonably liquid market exists for a given security that can be freely purchased by global investors, in which case it is listed as investable. The number of securities used to construct each investable index varies considerably across countries and to a lesser extent over time. ${ }^{9}$ Daily, investable index closing values denominated in U.S. dollars from 6/30/1995 to 1/10/2006 are used for: Argentina, Brazil, Chile, China, Czech Republic, India, Indonesia, Malaysia, Mexico, Philippines, Poland, South Africa, South Korea, Taiwan, Thailand, Turkey. As a global benchmark index U.S. dollar denominated closing values of the Morgan Stanley Capital International All Country World Index (ACWI) also from 6/30/1995 to 1/10/2006 are used. This broad, market capitalization-weighted index is comprised of over 2600 companies from more than 50 countries. ${ }^{10}$ Observations for New Years Day, Good Friday, and Christmas, which tend to be null. From 2720 daily closing values, continuous daily rates of return are computed using the natural log of the closing price relative to the previous day's closing price. From the 2719 daily returns, 2468 rolling alphas and betas are estimated and used in the option pricing model. ${ }^{11}$

\section{Country Alphas and Betas and Entry and Exit Dollar Values}

\section{A. Country Alphas and Betas}

To get a sense of which countries experienced the brunt of the Asian

9. For instance, some markets (i.e., Czech Republic) have fewer than ten investable securities, while others (i.e., Brazil) have more than two hundred.

10. See http://www.mscibarra.com/eqb/methodology/meth_docs/MSCI_May06_Index CalcMethod ology.pdf for a full description of how the index is created.

11. The formula to determine the number of estimates is $s=T-w-1=2719-250-$ 1. Estimates for June 19, 1996 and January 10, 2006 are lost because of the non-synchronous data bias adjustment since the first and last observations are lost when estimating the lagged and leading regressions. 


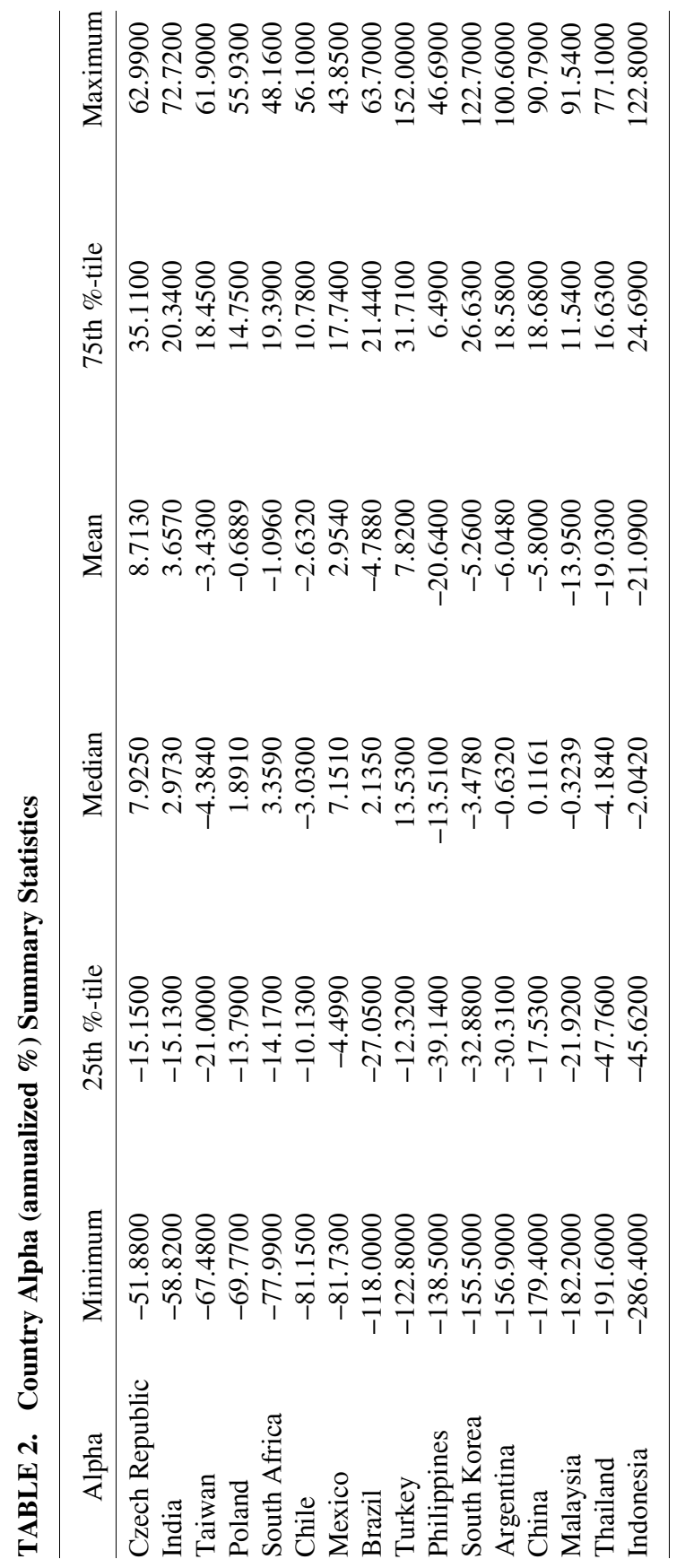




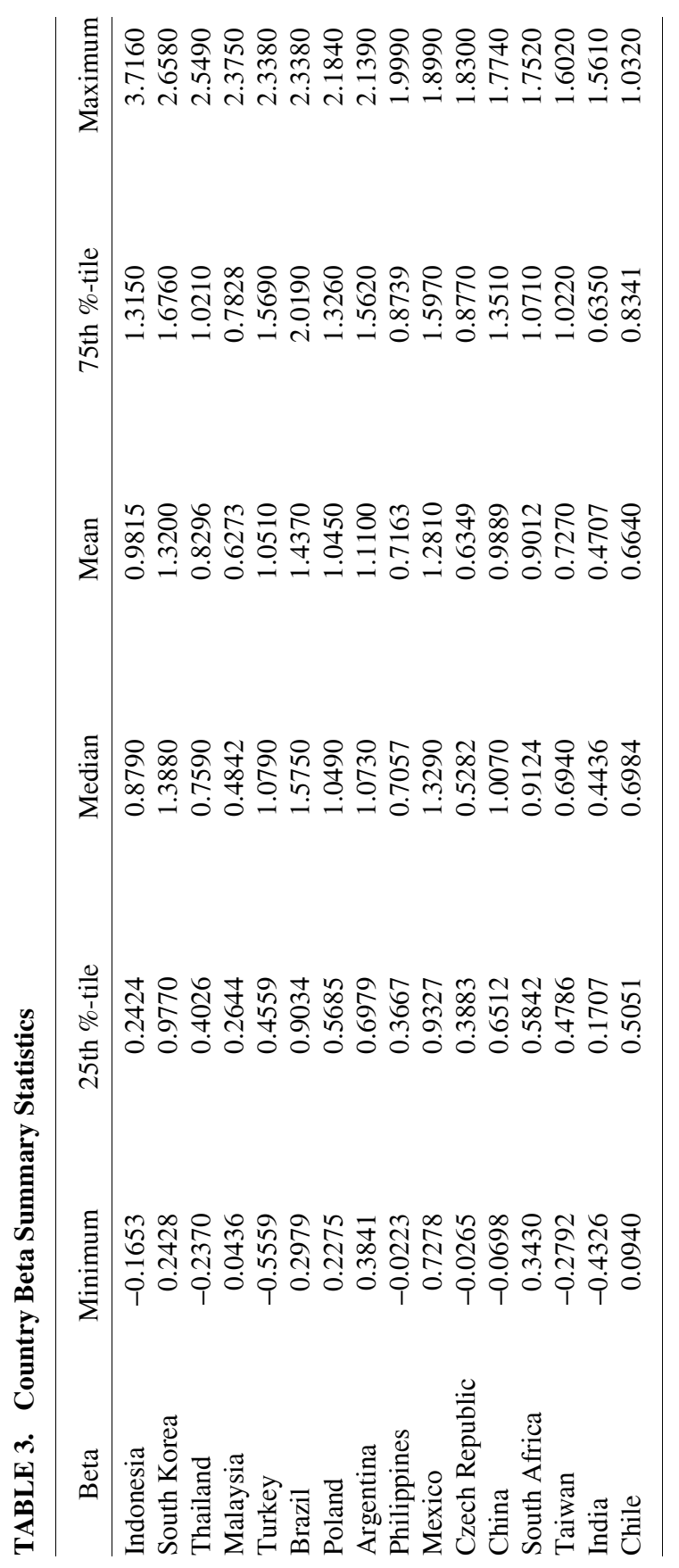


Crisis, table 2 reports summary statistics of the annualized alphas with countries ranked from smallest to largest maximum losses, as summarized by the minimum column. Countries in Europe generally fair better than those in Latin America, and the worst performance is observed in Asia, especially with Indonesia, Thailand, Malaysia, China and South Korea. The two notable exceptions in Asia are India and Taiwan, which in spite of maximum declines above $50 \%$ were relatively stable. Indonesia for instance experienced a maximum decline of almost 300\% during the Asian Crisis, while Thailand, Malaysia and China experienced maximum declines approaching $200 \%$.

Table 3 reports summary statistics for country betas with countries ranked from largest to smallest maximum values. From this you see that while Chile was at worst minimally riskier than the global benchmark, other markets ranged from being over one and a half times to almost four times as risky as the global index. By ranking them this way, country betas suggest that most of the countries that have the higher maximum betas over the sample also happen to be among the worst performing countries in table 2 .

\section{B.Generating Overnight Option Prices}

With the sample country risk-adjusted performance and risk in mind, the information content of the entry and exit pricing formulae can be motivated using the following thought experiment. Assume that each day at the close of business it is possible to purchase 250-trading day options that expire in two days, meaning that they could be exercised the next day. The entry exchange option would indicate the value of investing in a country the next morning, since it implies exchanging the global benchmark for the country index. The price of the exit exchange option reflects the value of disinvesting from a country overnight, since it implies exchanging the country for the global index. These values change over time. The volatility inputs for equations 18 and 22 are the country betas from equation 23 , the variance of the residuals computed according to equation 25 , and the global index volatility defined in equation 27. Index values are rescaled for each country and the MSCI ACWI to equal 100 on June 30, 1995, the first day for which the EMDB has recorded daily data. The realized country and global index ratios covering a 248-day period as $V_{k t} / V_{k, t-247}$ and $V_{w t} / V_{w, t-247}$ are computed, as are the 248-day ratios beginning on June 20, 1996 relative to July 6,1995 , and iterated forward until the last observation in the 
sample, calculated using values for January 9, 2006 relative to January 24,2005 . Inserting these inputs in the pricing formulas in equations 18 and 22 gives the implied prices of exiting and entering an emerging market.

\section{Entry and Exit Values}

Table 4 reports summary statistics for the exit option values with countries ranked by the largest to smallest maximum values during the sample. The mean values are above the median values indicating that the distributions are skewed. In terms of individual market performance, at the worst point of Indonesia's exposure to the Asian Crisis, investors would have been willing to pay over two dollars, for every dollar invested to exit the country, given the market's underperformance. That said the median value for Indonesia is not the highest, suggesting that the country experienced a brief but extreme shock. Contrast this with Taiwan, which has a higher median value over the sample, but a much lower maximum value, suggesting that investors generally assign a higher exit value than in Indonesia. Even in a relatively safer market like Taiwan, as well as Chile, India, and Czech Republic, investors would have paid 49-55 cents for every dollar invested to exit the country.

Table 5 reports summary statistics for the entry option values with countries ranked by the largest to smallest maximum values during the sample. Here again, the mean values are above the median values indicating that the distributions are skewed. In terms of individual market performance, Turkey stands out as investors at the peak would have been willing paid an addition $\$ 3.53$ for every dollar invested to get in because of the country's outperformance relative to the global benchmark. The Turkish median entry value is also almost twice that for the Czech market, the next highest during the sample.

To get a sense of the dynamics of the entry and exit values, figure 1 depicts the entry exchange option values and the negative of the exit exchange option values for Indonesia and Thailand. The vertical axis is scaled to include the maximum entry (Turkey) and minimum exit (Indonesia) exchange option values across all countries over the sample. From this you see that Indonesia experienced an extreme loss of market value, as investors sold off assets quickly. On the other hand, the Indonesian market seems to have rebounded as the exit value drops to zero after the crisis, while the entry value rises suddenly through 1999. 


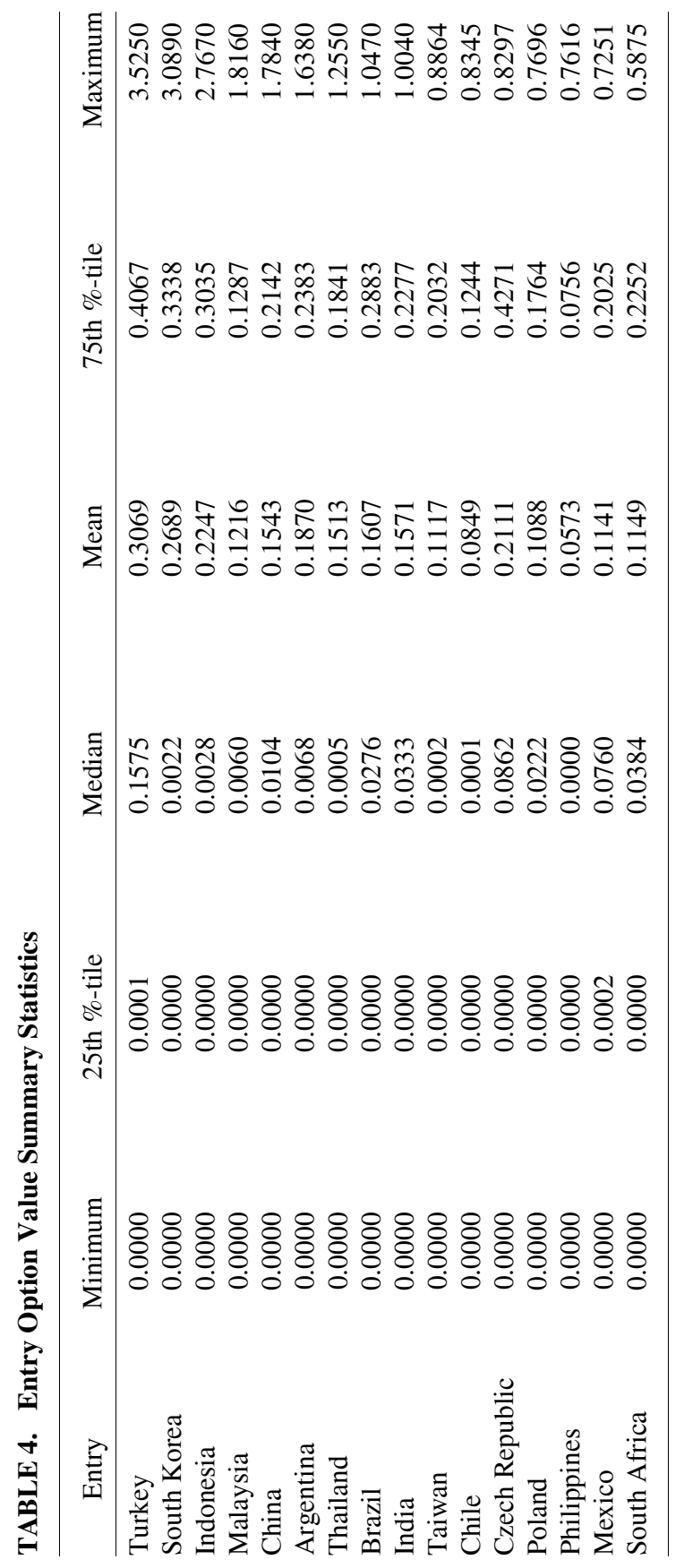




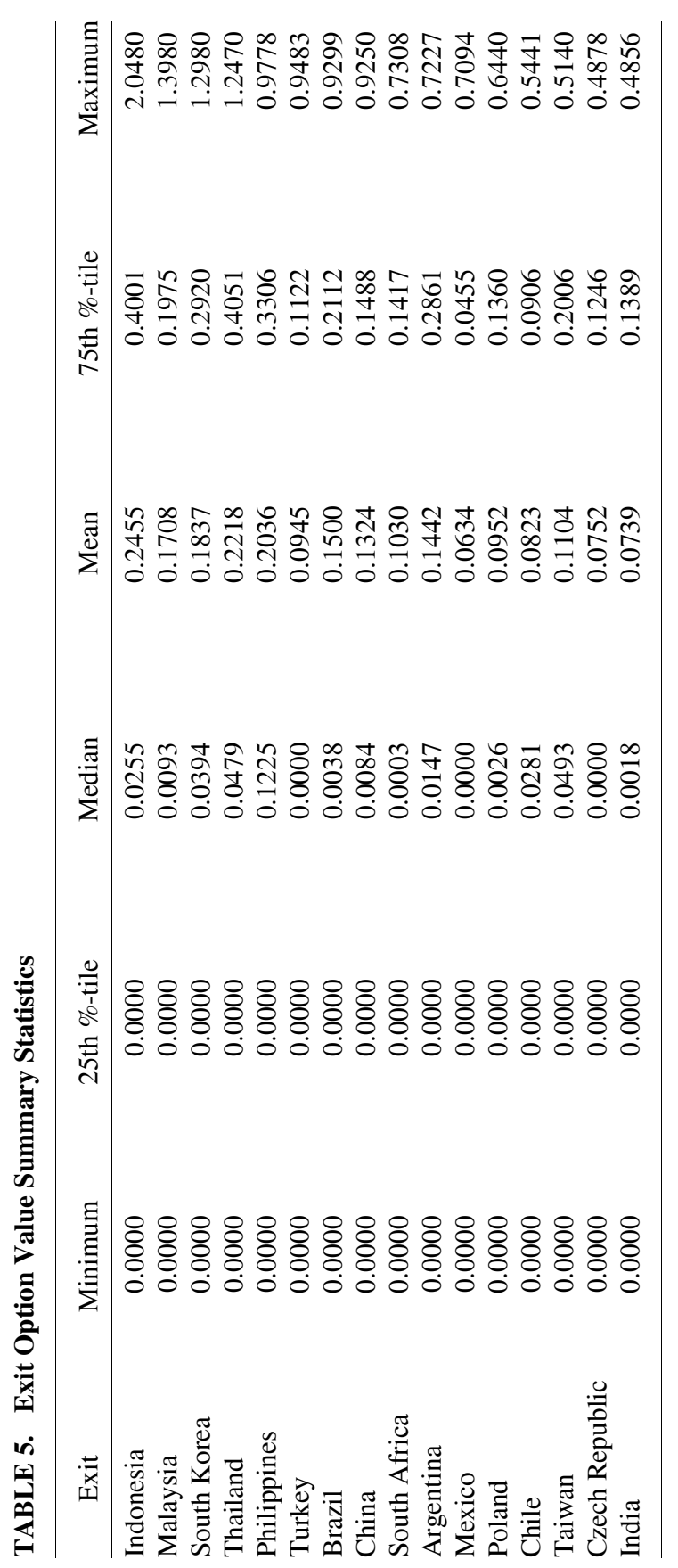




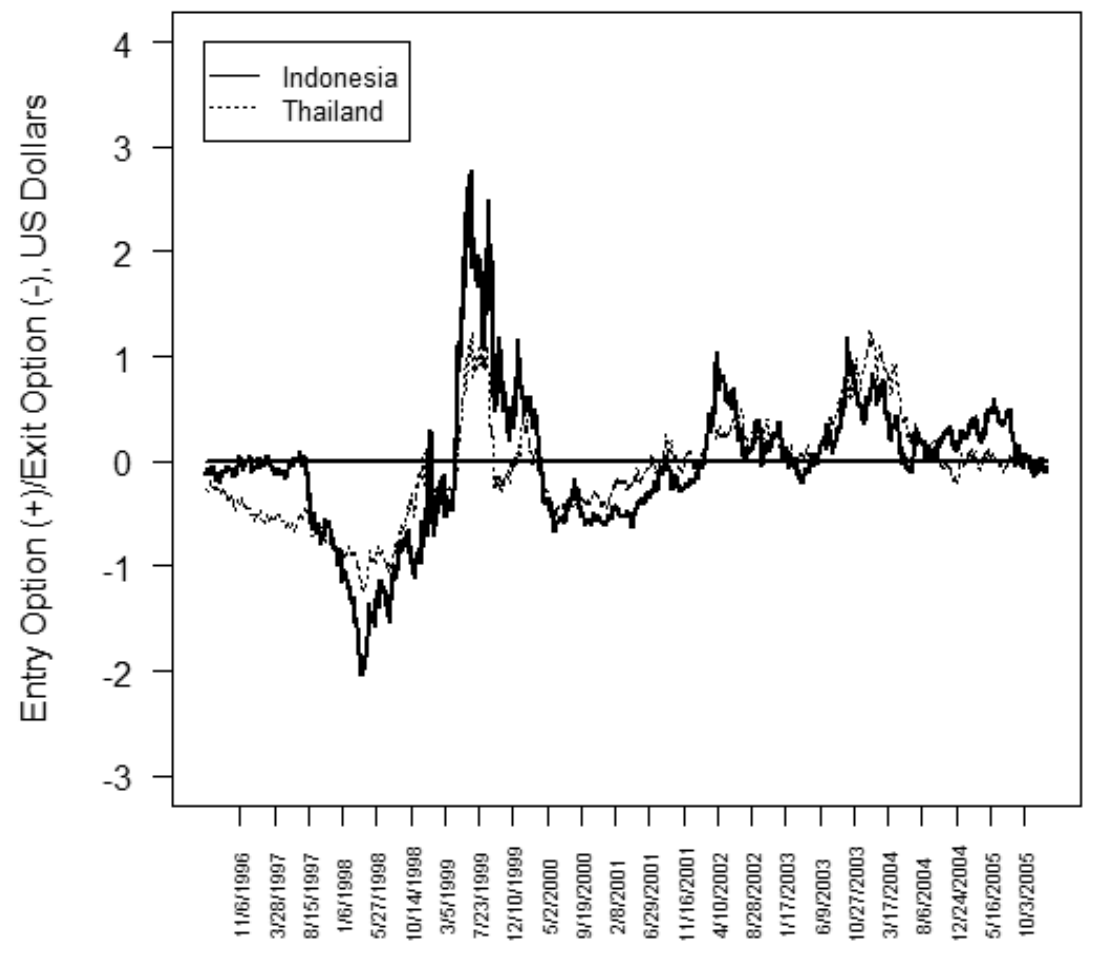

FIGURE 1.- Plots the Entry Option Values (above zero), and the negative of the Exit Option Values (below zero) for Indonesia and Thailand. The figure reveals the depth of the exposure to the crisis, but also the strong recovery after the crisis. It also suggests that investors were willing to leave Thailand already in 1996.

There is a similar pattern for Thailand. Interestingly, you see that the falling negative Thai exit values suggest that investors were willing to leave already in 1996, more than a year ahead of the July $2^{\text {nd }}$ baht crash.

Figure 2 depicts the entry and exit option values for Turkish and Polish markets the most extreme cases from the Europe, Middle East and Africa region; the vertical axis is again scaled to include the maximum and minimum values across all countries in the sample. While the exit values increased for Turkey during the Asian Crisis, there was a strong rebound in the market through 1999-2000. By way of contrast, the Polish market is fairly unremarkable in its stability. 


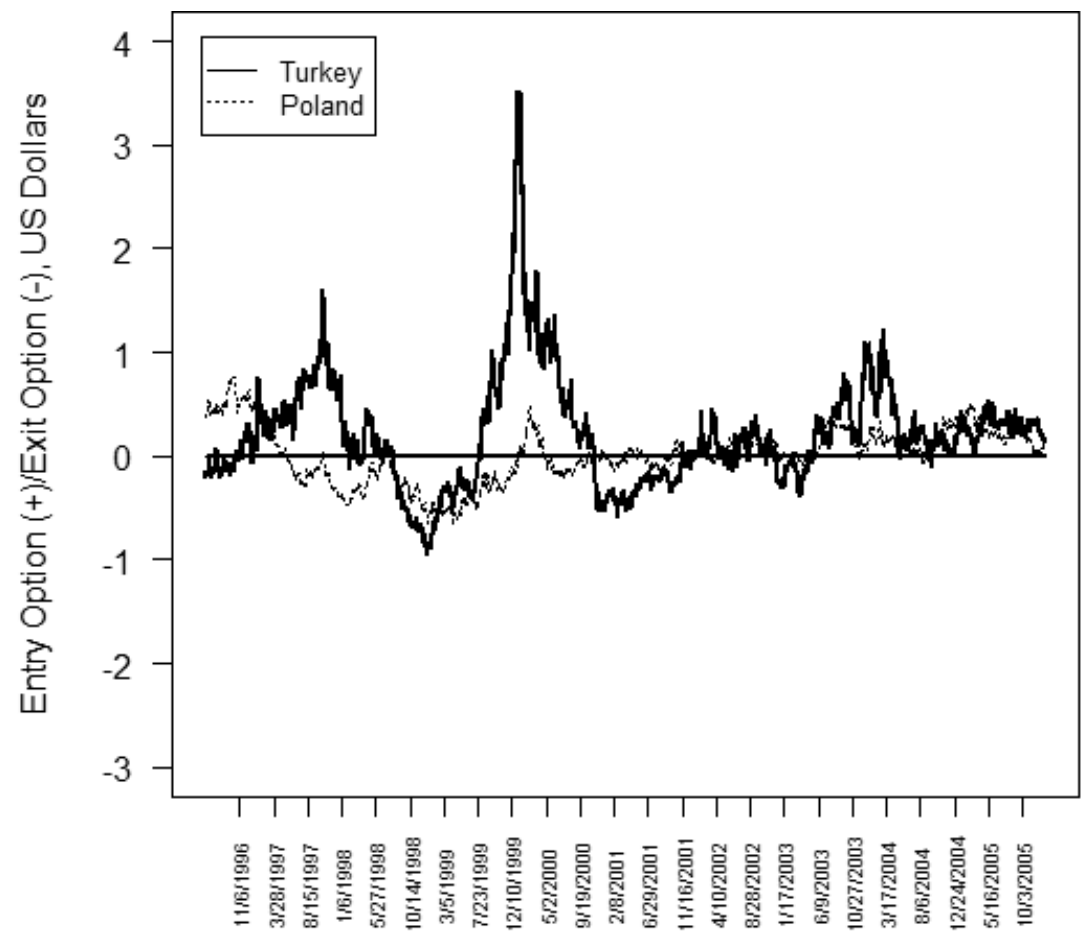

FIGURE 2.- Plots the Entry Option Values (above zero), and the negative of the Exit Option Values (below zero) for Poland and Turkey. While Turkey exhibits strong performance, Poland is relatively unremarkable in its stability.

Figure 3 depicts the entry and exit option values for Brazil and Mexico. Here again the vertical axis is scaled to include the maximum and minimum values across all countries in the sample. Mexico recovered fairly quickly from the Asian Crisis, while Brazil's exposure continued through 1999, dropping sharply after that. The range of observed values suggests that the region was relatively more stable than Asia.

Figure 4 depicts bi-variate plots of the difference between entry and exit option values against each country's alphas. This shows that when the entry option value is positive so is the alpha, and when the exit option value is positive, the alpha is negative. The non-linearity for each country reflects the fact that the alphas by construction are linear in the 


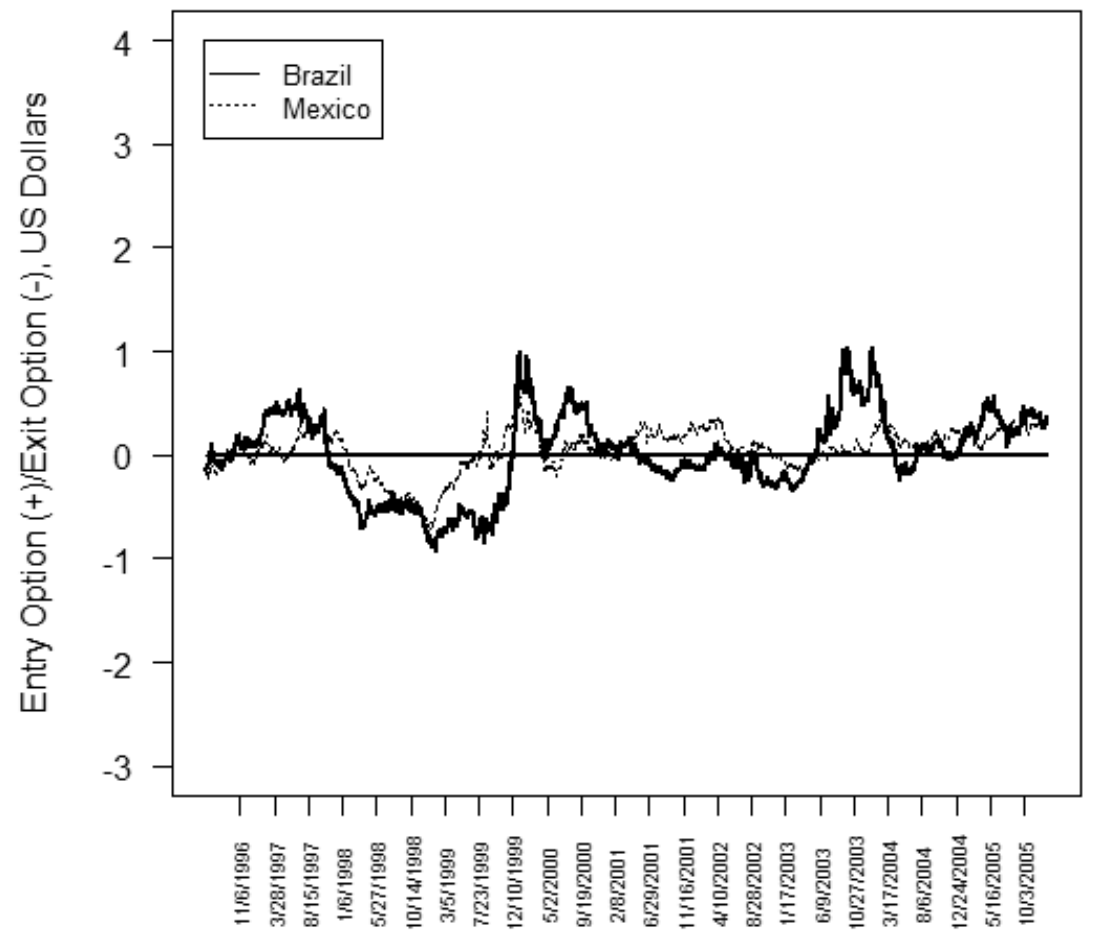

FIGURE 3.- Plots the Entry Option Values (above zero), and the negative of the Exit Option Values (below zero) for Brazil and Mexico. The figure reveals that the Mexican recovery occurred sooner than in Brazil, and also that markets in Latin American less volatile than in Asia.

betas, while the entry and exit exchange option values are non-linear in the betas.

Finally, figure 5 depicts bi-variate plots of the difference between entry and exit option values against each country's betas. Less volatile countries tend to have rounded and tightly concentrated points, whereas countries in crisis tend to have non-symmetric and disperse plots.

\section{Formal Tests}

To see how sensitive changes in entry and exit option values are to changes in country alphas and betas, the following least squares dummy variable regressions are estimated: 

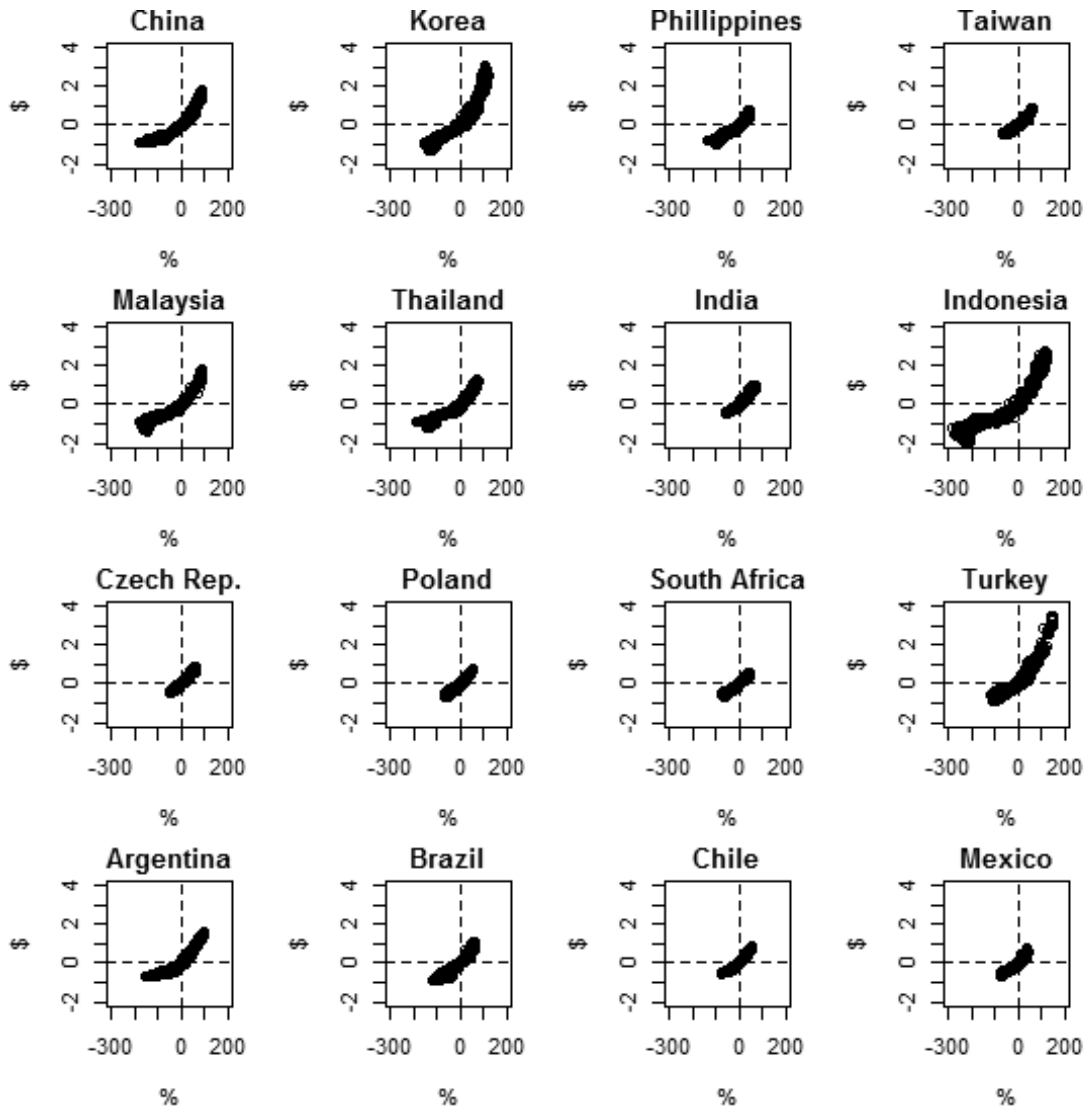

FIGURE 4.-Differences between the Entry and Exit Option Values Plotted Against the Annualized Alphas. The non-linearity in the plots arises in part because the alphas are linear in the betas while the benchmark premium and insurance payouts are non-linear in the betas.

$$
\begin{aligned}
\text { doption }_{k, t}= & b_{0}+\sum_{k=1}^{15} \delta_{k} \cdot d_{k}+\sum_{s=1}^{4} \delta_{s} \cdot \text { stage }_{s}+b_{1} \text { dalpha }_{k w t}+ \\
& \sum_{s=1}^{4} b_{s+1} \cdot \text { stage }_{s} \cdot \text { dalpha }_{k w t}+b_{6} \text { dbeta }_{k w t}+ \\
& \sum_{s=1}^{4} b_{s+6} \cdot \text { stage }_{s} \cdot \text { dbeta }_{k w t}+e_{k, t}
\end{aligned}
$$



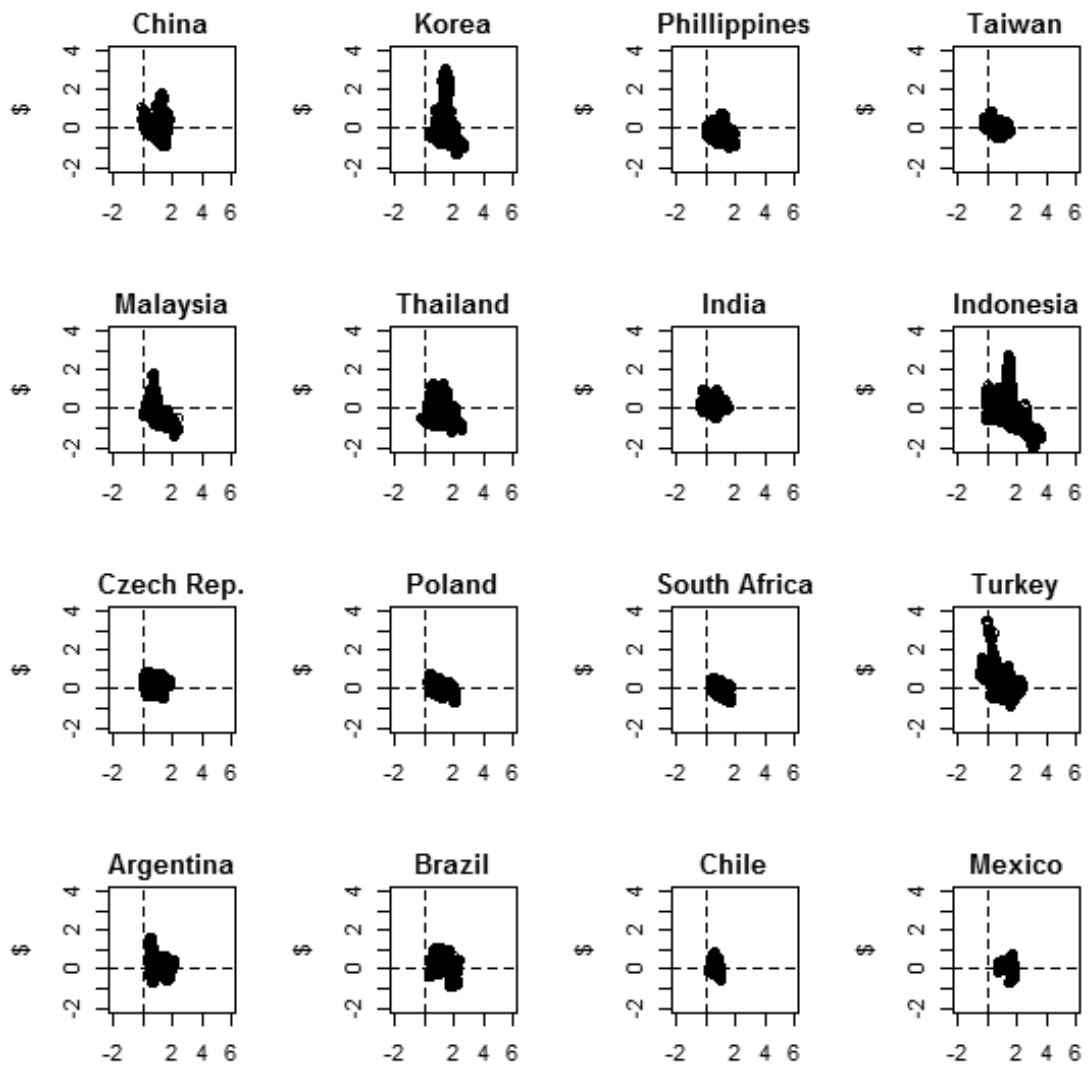

FIGURE 5.-Differences between the Entry and Exit Option Values Plotted Against the Betas. Countries less exposed to the Asian Crisis, have more concentrated and symmetric plots.

where doption $_{k, t}$ is the daily change in either country $k$ 's two-day entry or exit option value, $b_{0}+\sum_{k=1}^{15} \delta_{k} \cdot d_{k}$ is the intercept along with fifteen country dummy variables, with China serving as the benchmark, dalpha $_{k w t}$ is the daily change in country $k$ 's annualized alpha, dbeta $_{k w t}$ is the daily change in country $k$ 's beta, $\sum_{s=1}^{4} \delta_{s} \cdot$ stage $_{s}$ are dummy variables capturing each stage of the Asian Crisis, with stage 1 arising from the time of the Thai baht crash to the IMF bailout (7/2/97-1/16/98), stage 2 reflects the market volatility in the second quarter of 1998 
TABLE 6. Entry and Exit Option Value Sensitivities

\begin{tabular}{|c|c|c|}
\hline & Exit & Entry \\
\hline (Intercept) & $\begin{array}{c}-0.0001 \\
(0.0003)\end{array}$ & $\begin{array}{c}0.0002 \\
(0.0005)\end{array}$ \\
\hline South Korea & $\begin{array}{c}-0.0001 \\
(0.0004)\end{array}$ & $\begin{array}{c}-0.0001 \\
(0.0008)\end{array}$ \\
\hline Philippines & $\begin{array}{c}-0.0001 \\
(0.0004)\end{array}$ & $\begin{array}{c}0.0000 \\
(0.0011)\end{array}$ \\
\hline Taiwan & $\begin{array}{c}0.0000 \\
(0.0004)\end{array}$ & $\begin{array}{c}-0.0001 \\
(0.0006)\end{array}$ \\
\hline India & $\begin{array}{c}0.0000 \\
(0.0004)\end{array}$ & $\begin{array}{c}-0.0001 \\
(0.0006)\end{array}$ \\
\hline Indonesia & $\begin{array}{c}-0.0001 \\
(0.0007)\end{array}$ & $\begin{array}{c}-0.0001 \\
(0.0012)\end{array}$ \\
\hline Malaysia & $\begin{array}{c}0.0000 \\
(0.0005)\end{array}$ & $\begin{array}{c}-0.0002 \\
(0.0008)\end{array}$ \\
\hline Thailand & $\begin{array}{c}-0.0001 \\
(0.0005)\end{array}$ & $\begin{array}{c}-0.0001 \\
(0.0007)\end{array}$ \\
\hline Czech & $\begin{array}{c}0.0000 \\
(0.0004)\end{array}$ & $\begin{array}{c}-0.0001 \\
(0.0006)\end{array}$ \\
\hline Poland & $\begin{array}{c}0.0000 \\
(0.0004)\end{array}$ & $\begin{array}{c}-0.0001 \\
(0.0006)\end{array}$ \\
\hline South Africa & $\begin{array}{c}0.0000 \\
(0.0004)\end{array}$ & $\begin{array}{c}-0.0001 \\
(0.0006)\end{array}$ \\
\hline Turkey & $\begin{array}{c}-0.0002 \\
(0.0005)\end{array}$ & $\begin{array}{c}0.0000 \\
(0.0013)\end{array}$ \\
\hline Argentina & $\begin{array}{c}0.0000 \\
(0.0004)\end{array}$ & $\begin{array}{c}-0.0001 \\
(0.0007)\end{array}$ \\
\hline Brazil & $\begin{array}{c}-0.0001 \\
(0.0005)\end{array}$ & $\begin{array}{c}-0.0001 \\
(0.0008)\end{array}$ \\
\hline Chile & $\begin{array}{c}-0.0001 \\
(0.0003)\end{array}$ & $\begin{array}{c}-0.0001 \\
(0.0005)\end{array}$ \\
\hline Mexico & $\begin{array}{c}-0.0001 \\
(0.0003)\end{array}$ & $\begin{array}{c}-0.0001 \\
(0.0006)\end{array}$ \\
\hline stage1 & $\begin{array}{l}0.0015^{* * * *} \\
(0.0004)\end{array}$ & $\begin{array}{c}-0.0003 \\
(0.0006)\end{array}$ \\
\hline stage2 & $\begin{array}{l}-0.0025^{* * * *} \\
(0.0010)\end{array}$ & $\begin{array}{c}0.0001 \\
(0.0004)\end{array}$ \\
\hline stage 3 & $\begin{array}{c}-0.0036^{* * *} \\
(0.0015)\end{array}$ & $\begin{array}{c}-0.0001 \\
(0.0002)\end{array}$ \\
\hline stage4 & $\begin{array}{c}0.0050^{*} \\
(0.0030\end{array}$ & $\begin{array}{c}-0.0003 \\
(0.0017)\end{array}$ \\
\hline dalpha & $\begin{array}{l}-0.0170 * * * \\
(0.0044)\end{array}$ & $\begin{array}{l}0.0263 \text { ** } \\
(0.0113)\end{array}$ \\
\hline
\end{tabular}

( Continued) 
TABLE 6. (Continued)

\begin{tabular}{ccc}
\hline & Exit & Entry \\
\cline { 2 - 2 } dalpha x stage & -0.0153 & 0.0010 \\
& $(0.0168)$ & $(0.0221)$ \\
dalpha x stage2 & $-0.0515^{* *}$ & -0.0198 \\
& $(0.0241)$ & $(0.0185)$ \\
dalpha x stage3 & 0.0282 & $-0.0262^{* *}$ \\
dalpha x stage4 & $(0.0310)$ & $(0.0113)$ \\
dbeta & -0.0663 & -0.0278 \\
dbeta x stage1 & $(0.0612)$ & $(0.0196)$ \\
dbeta x stage2 & 0.0085 & $-0.1504 * * *$ \\
dbeta x stage3 & $(0.0070)$ & $(0.0229)$ \\
dbeta x stage4 & $0.1413 * * *$ & 0.0618 \\
& $(0.0268)$ & $(0.0470)$ \\
Adjusted R-Squared & $0.1941^{* *}$ & $0.1006^{* *}$ \\
Sample & $(0.0788)$ & $(0.0479)$ \\
& 0.0227 & $0.1504^{* * *}$ \\
& $(0.0805)$ & $(0.0230)$ \\
& $0.2909^{* *}$ & 0.0932 \\
& $(0.1157)$ & $(0.0580)$ \\
\hline
\end{tabular}

Note: The standard errors are estimated using the HAC covariance estimator. Stage 1 indicates the time from the Thai baht crash to the IMF bailout (7/2/97-1/16/98). Stage 2 indicates the market volatility in the second quarter of 1998 (4/1/98-6/30/98). Stage 3 corresponds with the Russian default (8/17/98-9/23/98). Stage 4 occurs during the brief turmoil associated with the Brazilian real devaluation (1/13/99-2/1/99).

(4/1/98-6/30/98), stage 3 occurs during the Russian default (8/17/98-9/23/98) and stage 4 occurs during the brief turmoil associated with the Brazilian real devaluation (1/13/99-2/1/99). These stage dummy variables are interacted with the changes in the alphas and betas to see how the sensitivity changes during the Asian Crisis. The estimated coefficients along the standard errors, adjusted using the Heteroscedasticity and Autocorrelation Consistent (HAC) covariance estimator, are reported in table 6.

The most important result in the context of this study is the relationship between changes in the exit and entry options to changes in the betas. Ordinarily, changes in the exit option values are unrelated to changes in the beta. However, this changes significantly during the Asian Crisis. In the first stage, exit options on average rise by 14 cents for every unit increase in the beta. During the second stage it is even 
higher at 19 cents for every unit increase in the beta. While the Russian default in stage 3 has little effect on exit option values, during the last stage following the Brazilian real problems, the exit options on average rise to 29 cents for every unit increase in the beta. So, country systematic risk is priced during the Asian Crisis. On the other hand, with respect to the entry options, you see the opposite, as there is ordinarily an inverse relationship with unit increases in the beta. However, during the Asian Crisis, the inverse relationship is largely eliminated.

The relationship between changes in the alpha and changes in the exit or entry options is not surprising. Ordinarily with increases in the alpha, exit option values fall while the entry option values rise. This makes sense since exit option values tend to rise when the alpha is negative, and entry option values tends to rise when the alpha is positive. By interacting the dummy variables with changes in the alpha, you can see that there is little change in the exit or entry option values. Unlike the asymmetric relationships between changes in entry or exit option values and changes in the country betas during the Asian Crisis, the roughly symmetric relationship between changes in the option values and changes in alphas largely reflects the fact that the two measures are constructed in a similar way.

\section{Conclusion}

While structured products have failed during the Tequila Crisis, the High Tech Crash and the Global Financial Crisis, structured finance offers the potential to hedge booms and busts in countries with options on systematic risk adjusted performance, which could be of use since the benefits of diversification may decline during a crisis. There are shortcomings. Among them, is the fact that if applied as is, the exit-entry values will be delayed because the Scholes-Williams alpha and beta estimates are not available until one day later, while the standard errors are not available until two days later, due to the leading regressions. One solution may be to omit those regressions to simplify the estimator. Also, it may be worth down-weighting earlier observations when estimating the rolling regressions to reduce the influence of older observed returns. Finally, an alternative to the method studied here would be to look at local currency denominated returns, to price the joint dynamics between the stock market and the exchange rate. 
Accepted by: Prof. P. Theodossiou, Editor-in-Chief, March 2013

\section{Acknowledgements}

I am grateful to the Editor, Professor Panayiotis Theodossiou, and two anonymous referees as well as Joe Reid, David M. Levy, Jot Yau, Jim Gentle, Peter Carr, Daniel Carrigan and Steven Malinsky at the Philadelphia Stock Exchange, Michel Dacorogna, Mark Tippett and Michalis Zervos, Kevin Davis, Emanuel Derman, Edgardo Favaro, Campbell Harvey, Steve Jewson, Robert Merton, Kurt Schuler, Ajay Shah, William Speth at the Chicago Board Options Exchange, Peter Tran, Susan Woodward, and seminar participants at the 2001 Ronald Coase Institute Workshop, the World Bank, the US Treasury Department, Monash University, Sydney University, the 2006 INFINITI conference at Trinity College, Dublin, and the 2006 FINSIA/Melbourne Centre Conference for valuable suggestions. Remaining errors should be attributed to me.

\section{Appendix: Calculating Alpha and Beta Standard Errors}

To construct the rolling variant of the Scholes-Williams beta reported in equation 25 , each day's "one-day leading", "contemporaneous" and "one-day lagging" regressions are

$$
\begin{gathered}
\left(\begin{array}{c}
r_{k, t} \\
r_{k, t-1} \\
\vdots \\
r_{k, t-249}
\end{array}\right)=\alpha_{k w t}^{+}\left(\begin{array}{l}
1 \\
1 \\
\vdots \\
1
\end{array}\right)+\beta_{k w t}^{+}\left(\begin{array}{c}
r_{w, t+1} \\
r_{w, t} \\
\vdots \\
r_{w, t-248}
\end{array}\right)+\left(\begin{array}{c}
e_{k, t}^{+} \\
e_{k, t-1}^{+} \\
\vdots \\
e_{k, t-249}^{+}
\end{array}\right) \\
\left(\begin{array}{c}
r_{k, t} \\
r_{k, t-1} \\
\vdots \\
r_{k, t-249}
\end{array}\right)=\alpha_{k w t}\left(\begin{array}{l}
1 \\
1 \\
\vdots \\
1
\end{array}\right)+\beta_{k w t}\left(\begin{array}{c}
r_{w, t} \\
r_{w, t-1} \\
\vdots \\
r_{w, t-249}
\end{array}\right)+\left(\begin{array}{c}
e_{k, t} \\
e_{k, t-1} \\
\vdots \\
e_{k, t-249}
\end{array}\right)
\end{gathered}
$$

and 


$$
\left(\begin{array}{c}
r_{k, t} \\
r_{k, t-1} \\
\vdots \\
r_{k, t-249}
\end{array}\right)=\alpha_{k w t}^{-}\left(\begin{array}{c}
1 \\
1 \\
\vdots \\
1
\end{array}\right)+\beta_{k w t}^{-}\left(\begin{array}{c}
r_{w, t-1} \\
r_{w, t-2} \\
\vdots \\
r_{w, t-250}
\end{array}\right)+\left(\begin{array}{c}
e_{k, t}^{-} \\
e_{k, t-1}^{-} \\
\vdots \\
e_{k, t-249}^{-}
\end{array}\right)
$$

where $r_{k, t}\left(r_{w, t}\right)$ is the day $t$ rate of return on the country (global) index, and $e_{k, t}$ is the day $t$ residual for that window of observations. Also required is the auto-correlation coefficient for the global benchmark for day $t$ is characterized as

$$
\left(\begin{array}{c}
r_{w, t} \\
r_{w, t-1} \\
\vdots \\
r_{w, t-249}
\end{array}\right)=\rho_{w t}\left(\begin{array}{c}
r_{w, t-1} \\
r_{w, t-2} \\
\vdots \\
r_{w, t-250}
\end{array}\right)+\left(\begin{array}{c}
e_{w, t} \\
e_{w, t-1} \\
\vdots \\
e_{w, t-249}
\end{array}\right)
$$

As the $\mathrm{AR}(1)$ estimator reports some null values, a least squares regression is used.

With the rolling country betas, and alphas, as well as the residual variances, the standard errors can be obtained as follows. First, for each window, a rolling measure of the correlation coefficient $\rho_{e_{k t}^{s}}=\frac{\sigma_{e_{k, t}^{s}, e_{k, t-1}^{s}}}{\sigma_{e_{k, t}^{s}} \sigma_{e_{k, t-1}^{s}}}$ is estimated for the residuals constructed according to equation 26. Another variable that Scholes and Williams (1977) prove is necessary to compute standard errors is the sum of lagged, current and leading realized rates of return on the world benchmark portfolio, $r_{3 w t}=r_{w, t-1}+r_{w, t}+r_{w, t+1}$. In using this variable, two additional observations, the full-sample endpoints, are lost from the final sample. A rolling autocorrelation coefficient for this variable, $\rho_{3 w t}=\frac{\sigma_{r_{3 w, t+1}, r_{3 w, t}}}{\sigma_{r_{3 w, t+1}} \sigma_{r_{3 w t}}}$, is required with $\sigma_{r_{3 w, t+1}}$ and $\sigma_{r_{3 w, t}}$ being the standard deviation of the new variable over the window being consider, and $\sigma_{r_{3 w, t 1}, r_{3 w, t}}$ being the covariance estimate between subsequent observations in that window. A third data point is lost from the sample in the process of estimating 
this parameter because it requires calculating the correlation between $r_{3 w, t+1}=r_{w, t}+r_{w, t+1}+r_{w, t+2}$ and $r_{3 w, t}=r_{w, t-1}+r_{w, t}+r_{w, t+1}$, and $r_{w, t+2}$ at the endpoint is out of sample. A rolling regression is estimated between $r_{w, t}, r_{3 w, t}$, denoted $\beta_{w t, 3 w t}=\frac{\sigma_{w t, 3 w t}}{\sigma_{3 w t}^{2}}$.

These inputs are used to construct the Scholes-Williams beta standard error

$$
\sigma_{\beta_{k w t}^{S}}=\sqrt{\frac{\sigma_{e_{k t}^{s}}^{2}}{\omega-2} \frac{1+2 \rho_{e_{k t}^{s}} \rho_{3 w t}}{\beta_{w t, 3 w t}^{2} \sigma_{r_{3 w, t}}^{2}}}
$$

where $\omega$ is the window size, which is chosen to equal 250 observations. This standard error is also a component of the alpha's standard error, which is computed as follows

$$
\sigma_{\alpha_{k w t}^{S}}=\sqrt{\left(\frac{\sigma_{e_{k t}^{S}}^{2}}{\omega-2} \frac{1+2 \rho_{e_{k t}^{S}} \rho_{3 w t}}{\beta_{w t, 3 w t}^{2} \sigma_{t^{\prime} w t}^{2}}\right) \bar{r}_{w, t-1, t-248}^{2}+\frac{\sigma_{e_{k t}^{S}}^{2}}{\omega-2}\left(1+2 \rho_{e_{k t}^{S}}\right)}
$$

\section{References}

Acker, D., and Duck, N. 2009. The effect of extreme markets on the benefits of international portfolio diversification. Multinational Finance Journal 13: 155-188.

Amin, K. I., and Bodurtha, J. N. 1995. Discrete-time valuation of American options with stochastic interest rates. Review of Financial Studies 8: 193-234.

Black, F., and Scholes, M. 1973. The pricing of options and corporate liabilities. Journal of Political Economy 81: 637-653.

Bodie, Z., and Merton, R. C. 2002. International pension swaps. Journal of Pension Economics and Finance 1: 77-83.

Bordo, M.; Mody, A.; and Oomes, N. 2004. Keeping capital flowing: the role of the IMF. International Finance 7: 421-450.

Butler, K., and Okada, K. 2008. Higher-order terms in bivariate returns to international stock market indices. Multinational Finance Journal 12: 127-155.

Chakrabarti, R., and Roll, R. 2002. East Asia and Europe during the 1997 Asian collapse: a clinical study of a financial crisis. Journal of Financial Markets 5: 1-30. 
Clark, E.; Gadad, M.; and Rousseau, P. 2010. Investor valuation of the abandonment option: empirical evidence from UK divestitures 1985-1991. Multinational Finance Journal 14: 291-317.

Draghi, M.; Giavazzi, F.; and Merton, R. C. Transparency, Risk Management and International Financial Fragility, Vol. 4. Geneva Reports on the World Economy. Geneva: International Center for Monetary and Banking Studies, 2003.

Edison, H., and Warnock, F. 2003. A simple measure of the intensity of capital controls. Journal of Empirical Finance 10: 81-103.

Fruhwirth, M.; Schneider, P.; and Schwaiger, M. 2007. Timing decisions in a multinational context: Implementing the Amin/Bodurtha Framework. Multinational Finance Journal 11: 157-178.

Girard, E., and Sinha, A. 2006. Does total risk matter? The case of emerging markets. Multinational Finance Journal 10: 117-151.

Harvey, C. R. 1995. The risk exposure of emerging equity markets. World Bank Economic Review: 19-50.

International Monetary Fund. 1998. The Asian Crisis: Capital Markets Dynamics and Spillover. Washington, D.C.: International Monetary Fund, International Capital Markets.

International Monetary Fund. 1999. Financial Sector Crisis and Restructuring: Lessons from Asia. Washington, D.C.: International Monetary Fund.

International Monetary Fund. 2003. Lessons from the Crisis in Argentina. Washington, D.C.: International Monetary Fund.

Jaeger, S., and Zimmermann, H. 1995. Economic cost of surplus insurance: An application of the Margrabe model. Finanzmarkt und Portfolio Management 9: 393-397.

Jensen, M. C., 1968. The performance of mutual funds in the period 1945 -1964. Journal of Finance 23: 389-416.

Kahya, E. 1997. Correlation of Returns in Non-Contemporaneous Markets. Multinational Finance Journal 1: 123-135.

Kaminsky, G., and Schmukler, S. 1999. What triggers market jitters? A chronicle of the Asian crisis. Journal of International Money and Finance 18: 537-560.

Latane, H., and Rendleman, R. 1976. Standard deviations of stock price ratios implied in option prices. Journal of Finance 31: 369-381.

McDonald, J. B.; Michelfelder, R.; and Theodossiou, P. 2009. Robust regression estimation methods and intercept bias: A capital asset pricing model application. Multinational Finance Journal 13: 293-321.

Margrabe, W. 1978. The value of an option to exchange one asset for another. The Journal of Finance 33: 177-186.

Merton, R. C., 1973. An intertemporal capital asset pricing model. Econometrica 41: 867-887.

1990. The financial system and economic performance.

Journal of Financial Services Research 4: 263-300. 
Miller, S. 2005. Betting on country alphas to hedge against Asian crisis risk. Journal of Risk Finance 6: 17-30.

Okunev, J., and Tippett, M. 1993. A multifactor option pricing model. Advances in Futures and Options Research 6: 67-80.

Ranaldo, A., and Haberle, O. 2008. Wolfe in sheep's clothing: the active investment strategies behind index performance. European Financial Management 14: 55-81.

Roll, R. 1988. The international crash of October 1987. Financial Analysts Journal: 19-35.

Scholes, M., and Williams, J. 1977. Estimating betas from non-synchronous data. Journal of Financial Economics 5: 309-327.

Siegel, A. 1995. Measuring systematic risk using implicit beta. Management Science 41: 124-128.

Solnik, B. 1974a. An equilibrium model of the international capital market. Journal of Economic Theory 8: 500-524.

. 1974b. The international pricing of risk: an empirical investigation of the world capital market structure. The Journal of Finance 29: 365-378.

Tabner, I. 2009. Benchmark Concentration: Capitalization Weights vs. Equal Weights in the FTSE 100 Index. Multinational Finance Journal 13: 209-228. 